Case Report

\title{
Bacterial Pleuritis with Thickened Mesothelial Hyperplasia in a Young Beagle Dog
}

\author{
Naoaki Yamada ${ }^{1 *}$, Satomi Hashimoto ${ }^{1}$, Yuki Tomonari ${ }^{1}$, Hiroko Kokoshima ${ }^{1}$, Takuya Doi ${ }^{1}$, \\ Junko Sato ${ }^{1}$, Yumi Wako, and Minoru Tsuchitani ${ }^{1}$ \\ ${ }^{1}$ Pathology Department, Kashima Laboratory, Nonclinical Research Center, Mitsubishi Chemical Medience Corporation, 14-1 \\ Sunayama, Kamisu, Ibaraki 314-0255, Japan
}

\begin{abstract}
A five-month-old male beagle dog suddenly became moribund. Bloody fluid accumulated in the thoracic and abdominal cavities, and soft yellow flecks were floating in the thoracic fluid. The mediastinum and pericardium became dark reddish with villous thickening. Other parietal and pulmonary pleurae were rough, and the organs adhered to each other. Histologically, most mediastinal pleura formed papillary projections covered by a single layer of mesothelial cells. Many macrophages and neutrophils infiltrated the submesothelial connective tissue. At the mediastinum adjacent to the pericardium, cuboidal mesothelial cells proliferated solidly and formed a thick surface stratum. The flecks consisted of gram-negative filamentous or small bacillary (coccoid) bacteria. In the right posterior lobe of the lung, neutrophilic infiltration and a large encapsulated abscess including a bacterial colony were present. We diagnosed this case as "bacterial pleuritis with thickened mesothelial hyperplasia". The cause of the pleuritis might be a chronic pleural infection spread via the lung abscess. (DOI: 10.1293/tox.26.313; J Toxicol Pathol 2013; 26: 313-317)
\end{abstract}

Key words: bacterial pleuritis, mesothelial hyperplasia, beagle dog, Escherichia coli, Serratia odorifera, Acinetobacter lwoffii

In dogs and cats, bacteria (such as Nocardia, Actinomyces, and Bacteroides) can cause pyogranulomatous pleuritis, and many species of bacteria can be present as either singular or mixed infection in pyothorax of dogs and cats $^{1,2}$. It is well known that persistent serosal injury such as chronic pleuritis induces mesothelial hyperplasia ${ }^{2-4}$. Moreover, an appropriate stimulus including inflammation transformed normal pavement mesothelial cells into a tumor-like activated mesothelium, which is a cuboidal and papillary outgrowth ${ }^{5}$. Here, we report a case of bacterial pleuritis in a young beagle dog accompanied by thickened mesothelial hyperplasia.

The animal was a 5-month-old male beagle dog. The beagle dog was purchased from Beijing Marshall Biotechnology Co., Ltd. (Beijing). The dog was housed in an animal room maintained at a temperature of $26 \pm 3^{\circ} \mathrm{C}$ and a humidity of $55 \pm 20 \%$. The dog was given $300 \mathrm{~g} /$ day DS-A (Oriental Yeast Co., Ltd., Tokyo, Japan) with free access to water. The dog was kept for a forthcoming study without any kind of treatment. Since the dog suddenly became less energetic and moribund without any clinical signs, it was

Received: 1 March 2013, Accepted: 7 May 2013

*Corresponding author: N Yamada (e-mail: yamada.naoaki@,

mn.medience.co.jp)

(C2013 The Japanese Society of Toxicologic Pathology

This is an open-access article distributed under the terms of the Creative Commons Attribution Non-Commercial No Derivatives (by-ncnd) License $<$ http://creativecommons.org/licenses/by-nc-nd/3.0/>. euthanized under pentobarbital sodium anesthesia and dissected. At necropsy, bloody fluid accumulated in the thoracic and the abdominal cavities. Many soft yellow flecks of approximately 5-mm in diameter were floating in the thoracic bloody fluid (Fig. 1A). The mediastinum and pericardium became dark reddish and thickened with a villous surface (Fig. 1B). The other pleural surfaces, such as the costal, diaphragmatic and pulmonary portions, were rough but not villous. The right posterior lobe of the lung adhered to the accessory lobe fibrously, the thymus adhered to the right anterior lobe of the lung, and the pericardium adhered to the mediastinum fibrinously. A nodule of about 2-mm in diameter was observed on the surface of the right anterior lobe of the lung. The diaphragm was perforated at the dorsal end of the right thorax. There was no perforation of the esophagus or rupturing of large vessels. No gross lesions were observed in the abdominal organs. The organs were fixed in $10 \%$ phosphate buffered formalin, trimmed, embedded in paraffin, sectioned and stained with hematoxylin and eosin (HE). Special-stainings such as Gram stain, Grocott's methenamine silver nitrate stain, periodic acid-Schiff stain and Ziehl-Neelsen stain (Fite method), and immunohistochemical staining for cytokeratin (Polyclonal Rabbit Anti-Cytokeratin, Wide Spectrum Screening, Dako Japan, Tokyo, Japan), vimentin (Monoclonal Mouse Anti-Vimentin Clone V9, Dako Japan, Tokyo, Japan) and PCNA (Monoclonal Mouse Anti-Proliferating Cell Nuclear Antigen Clone, Dako Japan, Tokyo, Japan) were also performed. The bloody fluid wiped from the surface of the mediastinum was used 


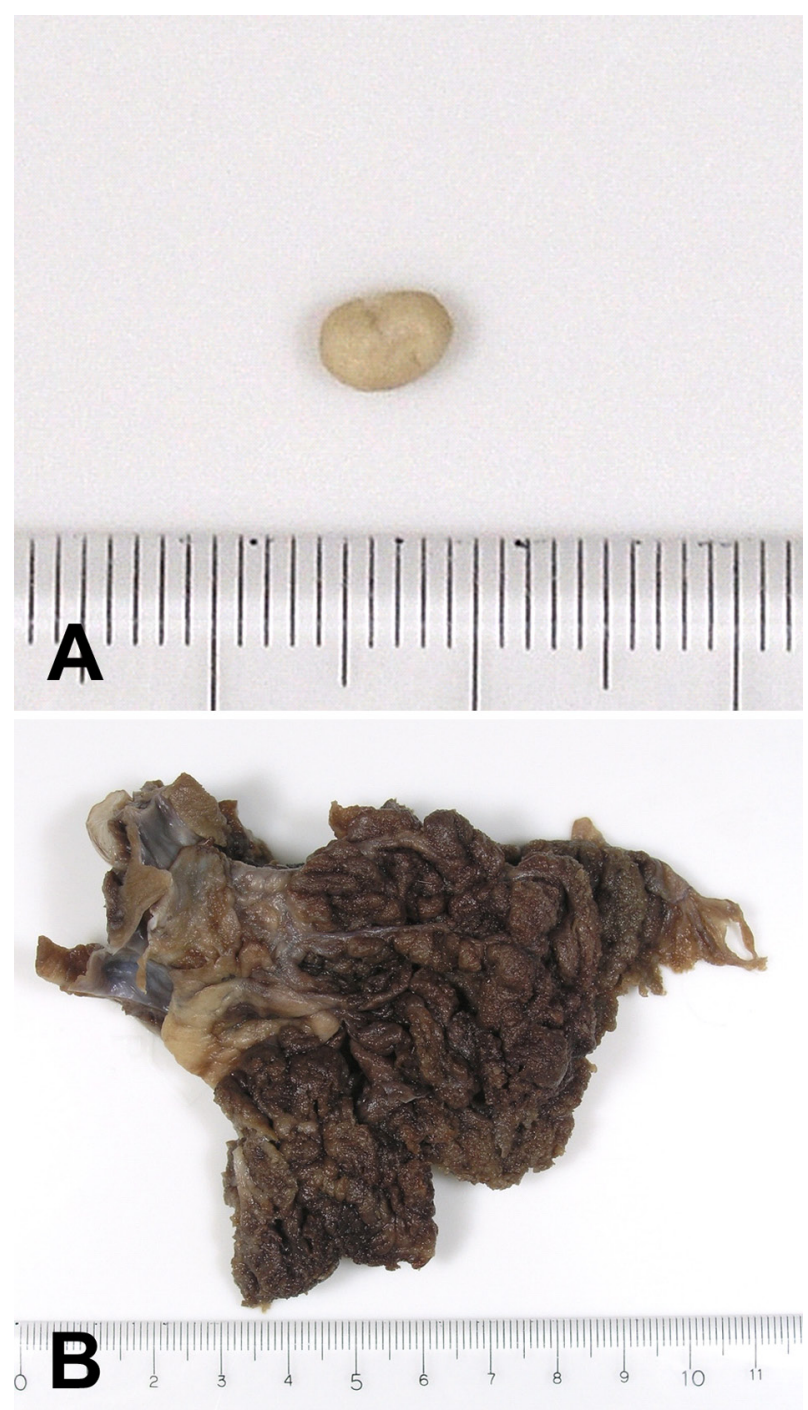

Fig. 1. Gross features of the pleuritis after $10 \%$ phosphate-buffered formalin. A: A soft yellow fleck floating in blood in the thorax cavity. B: The posterior mediastinum (right side of the picture) and pericardium (left side) exhibited villous thickening.

for the bacteriological examination with blood agar (VITEK 2 System, SYSMEX bioMérieux, Tokyo, Japan).

Histologically, most of the pleural surface of the mediastinum formed papillary projections covered by a single layer of mesothelial cells, which were cuboidal with round chromatin-rich nuclei and basophilic cytoplasm (Figs. 2A and B). Many macrophages and neutrophils and a small number of plasma cells and lymphocytes infiltrated the subpleural connective tissue of the mediastinum (Fig. 2B). There were many dilated capillaries accompanied by the fibrin thrombus within the vessels. The endothelial cells of the vessels were hypertrophic. Hemorrhage was frequently observed near the surface of the mediastinum. At the mediastinum adjacent to the pericardium, cuboidal mesothelial cells, which had the round chromatin-rich nuclei and basophilic cytoplasm, proliferated solidly and formed a thick surface stratum with dilated capillaries accompanied by the fibrin thrombus (Figs. $2 \mathrm{C}$ and $\mathrm{D}$ ). There was almost no morphological difference between the single layer of mesothelial cells and solid ones, and neither showed any atypia. Very few mitotic figures were observed in the solid ones. The pleural surface at the nodule in the right anterior lobe of the lung was also covered by solid proliferating mesothelial cells, while the other area of the lung was covered by a single layer of mesothelial cells with inflammatory cell infiltration. Immunohistochemically, all of the mesothelial cells reacted positively for cytokeratin (Figs. 2E and F) and vimentin. Many mesothelial cells and hypertrophic blood endothelial cells of vessels reacted positively for PCNA. Since the perforated part of the diaphragm did not show any other macroscopic abnormalities, a histopathological examination was not performed.

In the gap of papillary projections of the pleural surface, there were frequent large bacterial colonies corresponding to the soft yellow flecks observed in the thoracic fluid at necropsy. The bacteria in the colonies showed basophilic granular or filament-like appearances. In gram staining, gram-negative filamentous or small (coccoid) bacilli were observed (Figs. 3A and B). No fungi or acid-fast bacilli were revealed by periodic acid-Schiff staining, Grocott's methenamine silver nitrate staining or Ziehl-Neelsen staining (Fite method). In the right posterior lobe of the lung, extensive neutrophilic infiltration and a large encapsulated abscess were present (Fig. 3C). There was a large bacterial colony in the center of this abscess. The abscess reached to the adhered part between the posterior and accessory lobe. Escherichia coli, Serratia odorifera and Acinetobacter lwoffii were isolated from the blood wiped from the surface of the mediastinum.

We diagnosed this case as "bacterial pleuritis with thickened mesothelial hyperplasia". If solid mesothelial proliferation is present without evident inflammation or a stimulative agent in a specimen, it becomes confused with mesothelioma because there are no histological criteria or markers for distinguishing the hyperplasia from neopla$\operatorname{sia}^{3,5}$. No single feature can be used to differentiate between activated and neoplastic mesothelial cells ${ }^{6}$. However, we believe that the mesothelial proliferation occurred in response to primary inflammation of the thoracic cavity for the following reasons: First, the present case had chronic pleuritis accompanied by bacteria. Inflammation can stimulate mesothelial activation resulting in non-neoplastic proliferation and transformation of pavement-type mesothelial cells into cuboidal or columnar cells ${ }^{5}$. Second, a large part of the thickened mediastinum was occupied by inflammatory cells and blood vessels and covered by a single layer of mesothelial cells. Third, solid mesothelial proliferation existed in a part of the pericardium surface. Invasion into the adjacent connective tissue and atypical mesothelial cells were not observed. Finally, mesothelioma has been found mostly in older $\operatorname{dogs} s^{7-11}$. In addition, we surmised that perforation of the diaphragm resulted in the dog becoming moribund, and it did not take long for the dog to become moribund after 

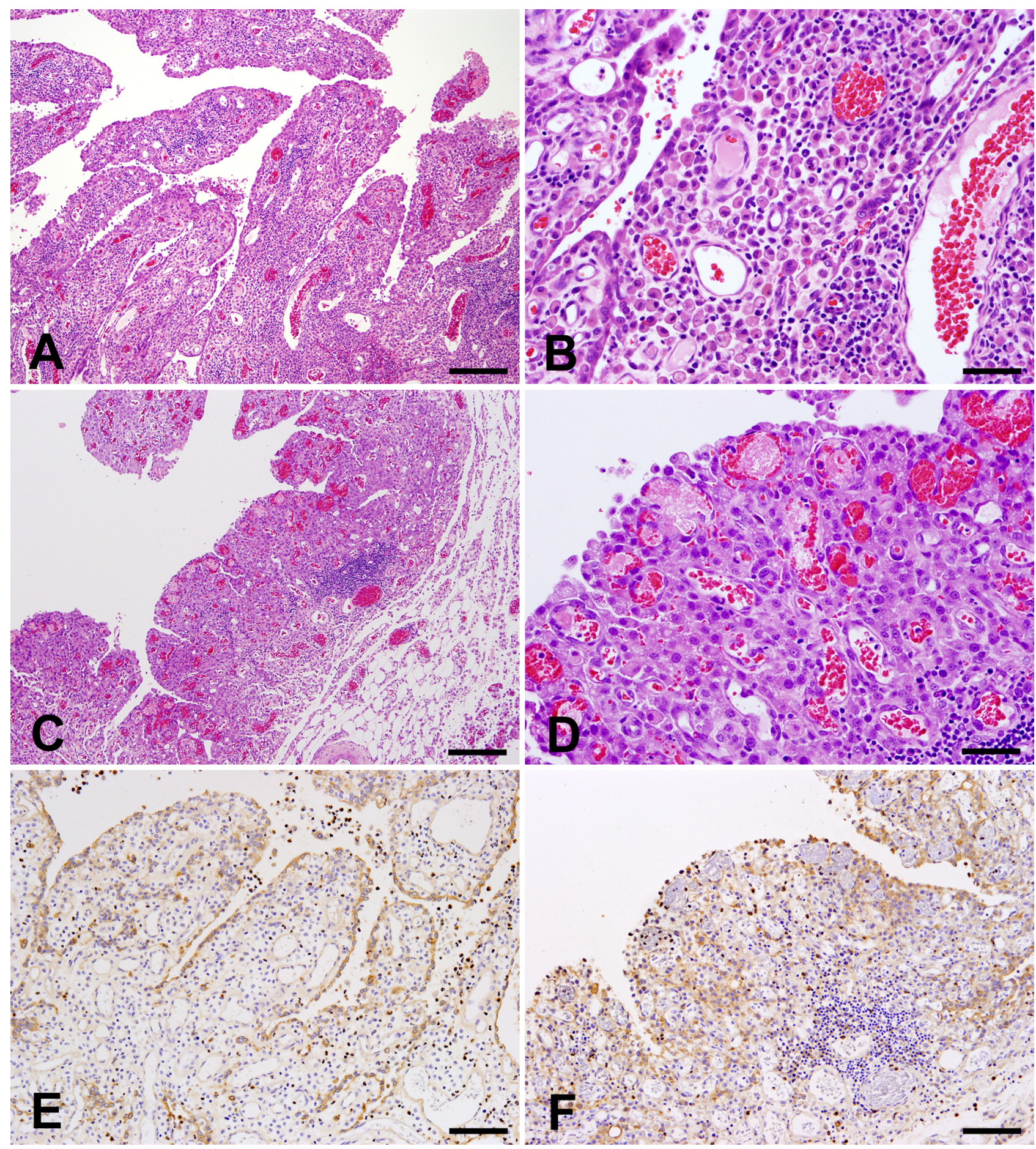

Fig. 2. The mediastinum. A: The mediastinum formed papillary projections. HE stain. Bar $=200 \mu \mathrm{m}$. B: Higher magnification of Fig. $2 \mathrm{~A}$ Many macrophages and neutrophils infiltrated in the submesothelial connective tissue of the mediastinum. The mediastinum was covered by a single layer of mesothelial cells. HE stain. Bar $=50 \mu \mathrm{m}$. C: The mediastinum of the pericardium. The mesothelial cells proliferated solidly and formed a thick surface stratum with infiltration of macrophages and proliferation of capillaries. HE stain. Bar $=200 \mu \mathrm{m}$. D: High magnification of Fig. 2C. There was almost no morphological difference between the single layer of mesothelial cells and solid mesothelial cells. HE stain. Bar $=50 \mu \mathrm{m}$. E: Immunohistochemically, the mesothelial cells that covered the surface of the mediastinum were cytokeratin positive. Immunohistochemical staining of cytokeratin. Bar $=100 \mu \mathrm{m}$. F: The mesothelial cells forming the thick surface stratum were also cytokeratin positive. Immunohistochemical staining of cytokeratin. Bar $=100 \mu \mathrm{m}$.

perforation. This is because there were no reactions in the serosal surface of abdominal organs that were submerged in the bloody fluid. However, the relationship of the perfora- tion and pleuritis remained unclear.

It is certain that the pleuritis in the present case was caused by bacterial infection, because bacterial colonies 

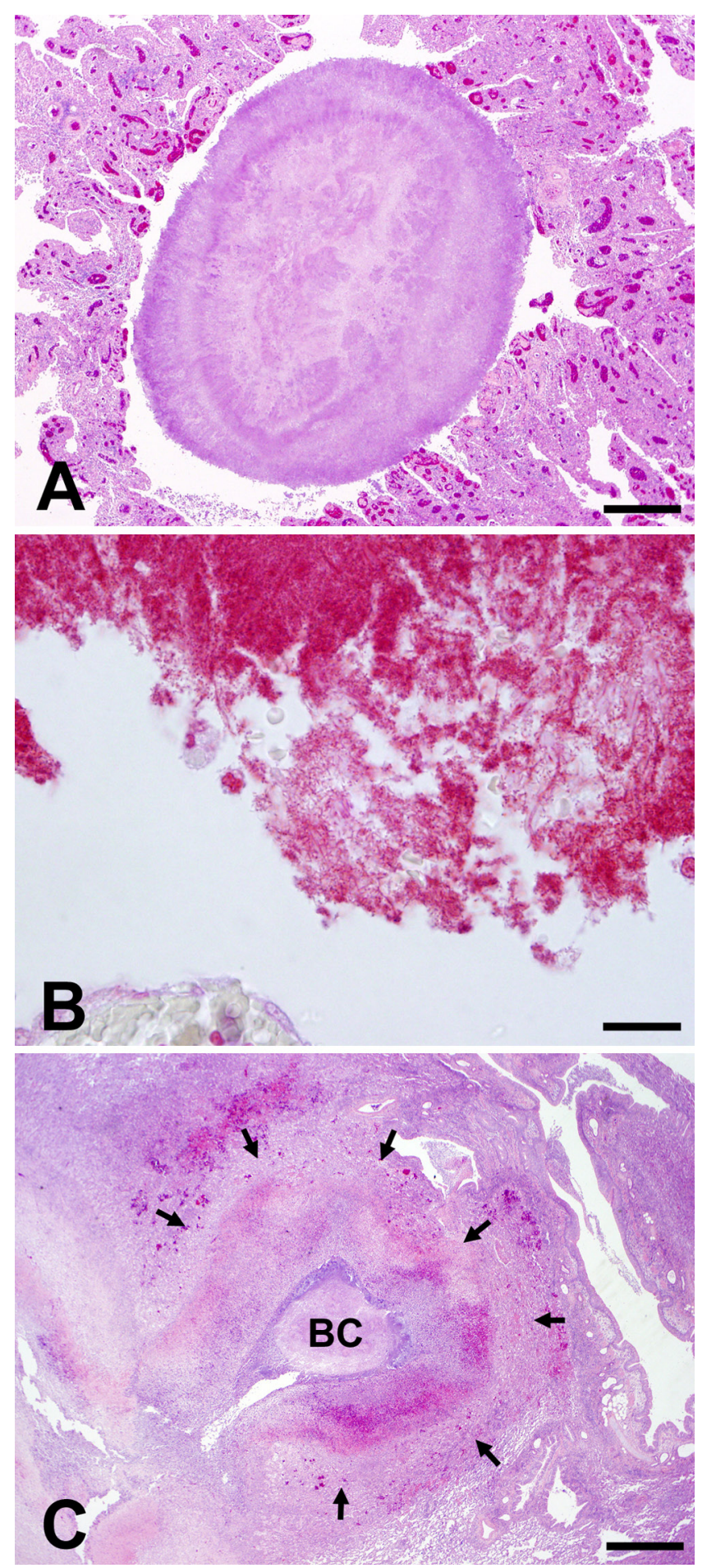

Fig. 3. A soft yellow fleck and lung abscess. A: The soft yellow fleck consisted of bacteria. HE stain. Bar $=500 \mu \mathrm{m}$. B: The bacteria were granular or filament-like and were gram-negative. Gram stain. Bar $=20 \mu \mathrm{m}$. C: In the right posterior lobe of the lung, a large encapsulated abscess was present (arrows). A large bacterial colony was in the center of this abscess (BC). HE stain. Bar $=1 \mathrm{~mm}$. were present and gram-negative bacteria, Escherichia coli, Serratia odorifera and Acinetobacter lwoffii, were isolated from the surface of mediastinum. Escherichia coli and Acinetobacter lwoffii exist in the environment or normal bacterial flora ${ }^{12}$. The natural reservoir of Serratia odorifera is still unknown, but most strains have been isolated from clinical human specimens and food ${ }^{13}$. Thus, the pleuritis in the present case was considered to have occurred as a result of incidental opportunistic infection. We surmised that the bacteria spread via the surface of the right posterior lobe of the lung, where the large abscess including the bacterial colony was present, and reached the surface. The cause of the lung abscess might be incidental aspiration, since there was primarily suppurative pneumonia in the right posterior lobe likely due to the bacteria existing in the environment and normal flora.

Acknowledgments: We would like to thank Dr. Masako Imaoka of Daiichi Sankyo Co., Ltd. for helpful comments on this report. The authors also thank Mr. Steve Yamakami and Ms. Kanae Tamatsukuri for language editing.

\section{References}

1. Alfonso L. Inflammation of the Pleura. In: Pathologic Basis of Veterinary Disease, 5th ed. JF Zachary, and MD McGavin (eds). Elsevier, St. Louis. 536-537. 2012.

2. Caswell JL, and Williams KJ. Pleura. In: Jubb, Kennedy, and Palmer's Pathology of Domestic Animals, Vol. 2, 5th ed. MG Maxie (ed). Elsevier Saunders, Philadelphia. 575578. 2007.

3. Battifora $\mathrm{H}$, and McCaughey WTE. Reactive processes in the serosal membranes. In: Atlas of Tumor Pathology, Tumors of the Serosal Membranes. B Hector, and WT McCaughey (eds). Armed Forces Institute of Pathology, Washington, D.C. 9-14. 1994.

4. Davila RM, and Crouch EC. Role of mesothelial and submesothelial stromal cells in matrix remodeling following pleural injury. Am J Pathol. 142: 547-555. 1993. [Medline]

5. Head KW, Cullen JM, Dubielzig RR, Else RW, Misdorp W, Patnaik AK, Tateyama S, and van der Gaar I. Tumors of serosal surfaces (pleura, pericardium, peritoneum, and tunica vaginalis). In: Histological Classification of Tumors of the Alimentary System of Domestic Animals. FY Schulman (ed). The Armed Forces Institute of Pathology in Cooperation with American Registry of Pathology and the World Health Organization Collaborating Center for Worldwide Reference on Comparative Oncology, Washington, DC. 144-148. 2003.

6. Head KW, Else RW, and Dubielzig RR. Tumor of serosal surfaces. In: Tumors in Domestic Animals, 4th ed. DJ Meuten (ed). Iowa State Press, Ames. 477-478. 2002.

7. Carlton WW. Neoplasms of the heart and blood vessels. In: Pathology of the Aging Dog, Vol. 2. U Morh, WW Carlton, DL Dungrworth, SA Benjamin, CC Capen, and FF Hahn (eds). Iwoa State University Press, Ames. 108-117. 2001.

8. Espino L, Vazquez S, Faílde D, Barreiro A, Miño N, and Goicoa A. Localized pleural mesothelioma causing cranial vena cava syndrome in a dog. J Vet Diagn Invest. 22: 309 
312. 2010. [Medline]

9. Brower A, Herold LV, and Kirby BM. Canine cardiac mesothelioma with granular cell morphology. Vet Pathol. 43: 384-387. 2006. [Medline]

10. Seo KW, Choi US, Jung YC, Hong SJ, Byeun YE, Kang MS, Pachrin B, Kim WH, Hwang CY, Kim DY, Youn HY, and Lee CW. Palliative intravenous cisplatin treatment for concurrent peritoneal and pleural mesothelioma in a dog. $\mathrm{J}$ Vet Med Sci. 69: 201-204. 2007. [Medline]

11. Reggeti F, Brisson B, Ruotsalo K, Southorn E, and Bienzle D. Invasive epithelial mesothelioma in a dog. Vet Pathol. 42:
77-81. 2005. [Medline]

12. Houang ET, Sormunen RT, Lai L, Chan CY, and Leong AS. Effect of desiccation on the ultrastructural appearances of Acinetobacter baumannii and Acinetobacter lwoffii. J Clin Pathol. 51: 786-788. 1998. [Medline]

13. Stock I, Burak S, Sherwood KJ, Gruger T, and Wiedemann B. Natural antimicrobial susceptibilities of strains of 'unusual' Serratia species: S. ficaria, S. fonticola, S. odorifera, S. plymuthica and S. rubidaea. J Antimicrob Chemother. 51: 865-885. 2003. [Medline] 